\title{
The Impact of Information Culture on Patient Safety Outcomes
}

\section{Development of a Structural Equation Model}

\author{
Virpi Jylhä1; Santtu Mikkonen2; Kaija Saranto1; David W. Bates ${ }^{3,4}$ \\ 'Department of Health and Social Management, University of Eastern Finland, Kuopio, Finland; \\ ${ }^{2}$ Department of Applied Physics, University of Eastern Finland, Kuopio, Finland; \\ ${ }^{3}$ Division of General Medicine and Primary Care and Department of Medicine, Brigham and Women's Hospital, \\ Harvard Medical School, Boston, MA, USA; \\ ${ }^{4}$ Partners HealthCare Information Systems, Division of Clinical and Quality Analysis, Wellesley, MA, USA
}

\begin{abstract}
Keywords
Information management, patient safety, adverse events, medication administration error, patient complaint, survey, health information technology
\end{abstract}

\section{Summary}

Background: An organization's information culture and information management practices create conditions for processing patient information in hospitals. Information management incidents are failures that could lead to adverse events for the patient if they are not detected.

Objectives: To test a theoretical model that links information culture in acute care hospitals to information management incidents and patient safety outcomes.

Methods: Reason's model for the stages of development of organizational accidents was applied. Study data were collected from a

Correspondence to:

Virpi Jylhä, PhD

Department of Health and Social Management

University of Eastern Finland

P.O. Box 1627

FI-70211 Kuopio

Finland

E-mail: virpi.jylha@hotus.fi cross-sectional survey of 909 RNs who work in medical or surgical units at 32 acute care hospitals in Finland. Structural equation modeling was used to assess how well the hypothesized model fit the study data.

Results: Fit indices indicated a good fit for the model. In total, 18 of the 32 paths tested were statistically significant. Documentation errors had the strongest total effect on patient safety outcomes. Organizational guidance positively affected information availability and utilization of electronic patient records, whereas the latter had the strongest total effect on the reduction of information delays.

Conclusions: Patient safety outcomes are associated with information management incidents and information culture. Further, the dimensions of the information culture create work conditions that generate errors in hospitals.

Methods Inf Med 2017; 56(Open): e30-e38 https://doi.org/10.3414/ME16-01-0075 received: June 17,2016 accepted: January 25, 2017 published: March 8, 2017 Funding

Part of this research received funding from the European Union's Seventh Framework Program (FP7/2007-2013) under grant agreement $n^{\circ} 223468$.

\section{Background}

Health-care professionals need accurate patient information, although what is needed varies by phase of care. How a hospital organizes information management is guided by national law and the technological tools, policies, and methods used in the organization; however, information culture practices, and 3) information behaviors ogy practices, 2 ) information management
og

also has a defining influence on how information is shared and used [1].

Information culture reflects the or zation's values, norms, and practices fo managing information $[2,3]$; thus, concept can be understood as a representation of three types of information capabilities [1, 2, 3, 4]: 1) information technol- and values. Information technology practices refer to the organization's capability to effectively manage information technology applications, software, and infrastructure [1]; information behaviors and values refer to "the capability to instill and promote behaviors and values in the people for effective use of information"; and information management practices are defined as "the capability to manage information effectively over the life cycle of information use, including sensing, collecting, organizing, processing, and maintaining information" $[1,4]$.

Information management is a continuous cycle of six closely related activities: identifying information needs, acquiring information, organizing and storing information, developing information products and services, distributing the information, and using the information [5]. Analyses of adverse event reports have shown that failures in the information management process - especially in medication management leading to medication administration errors - are prevalent in hospitals and that preventive actions are needed [6, 7]. Medication administration errors are frequent among hospital inpatients $[8,9]$. Health professionals base their decisions and actions on information available at the time [10]. Failures in written communication and errors in documentation have been identified as underlying system factors that contribute to medication administration errors [11]. Communication practices are affected by management decisions and information culture, and factors external to health professionals might lead to errors [10]. Consequently, the causes of errors are not just the responsibility of the individual nurse or physician but also of the hospital 


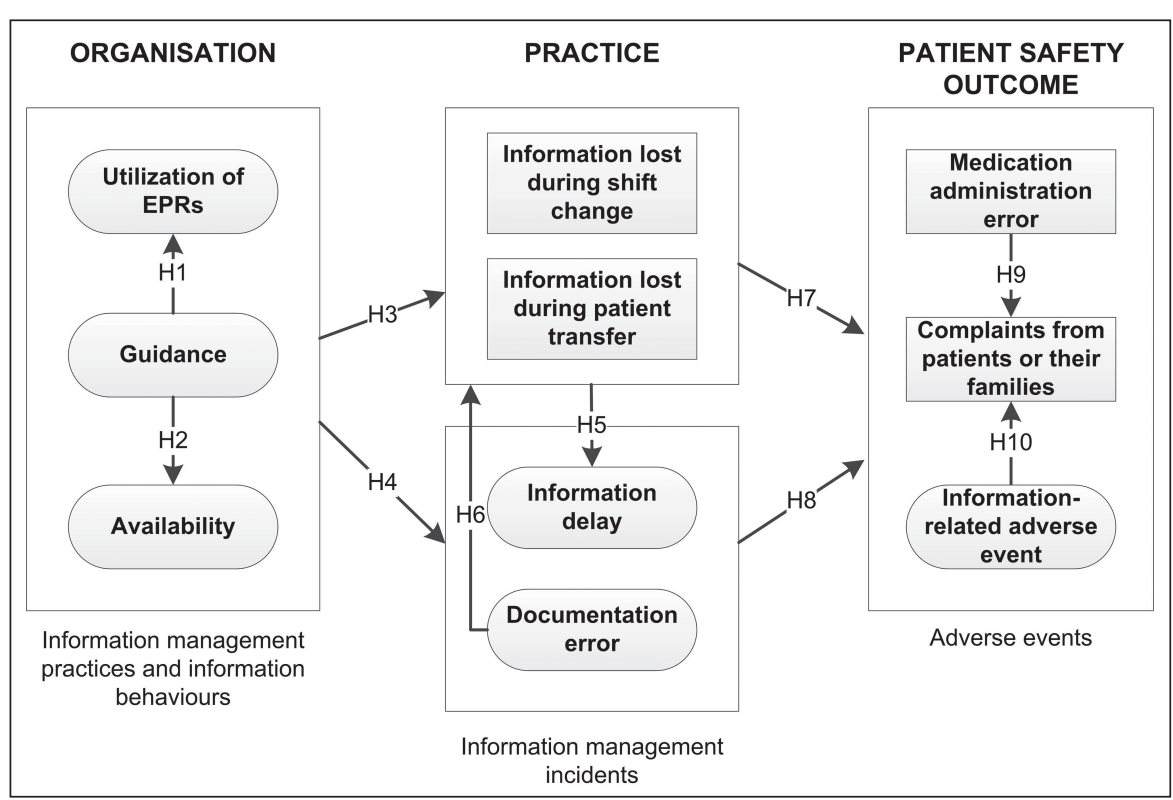

Figure 1 Hypothesized model modified from Reason's model for the stages of development of organizational accidents [13]. $\mathrm{H}$ refers to the hypotheses presented in this study.

that forms the system within which the providers function $[12,13]$. Further, preventing errors requires identifying organizational factors that lead to conditions that generate errors in care and thus affect outcomes [13].

The conceptual framework of this study (the hypothesized model shown in $\mathbf{D F}$ Figure 1) builds on Reason's model for the stages of development of organizational accidents (also called "the Swiss cheese model") and is applied to the context of information management in hospitals [13]. The model is recommended as a framework for adverse event studies [10] and is widely used in patient safety research to analyze the causes of and the factors that contribute to adverse events $[10,11,14$, 15]. The model focuses on the environment in which the health professional was working when an adverse event occurs rather than blaming the individual health professional [10]. The model describes how organizational factors, such as information management practices and information behaviors, can promote conditions that generate errors, which are defined as information management incidents in this study, and how these conditions impact patient safety outcomes. Information management incidents are failures that could lead to adverse events if the incidents are not de- tected. These incidents are related most often to deficiencies in information transfer during different phases of care and inadequate written communication; both types have been identified as conditions that generate errors in care $[11,16,17,18]$. Based on previous results of adverse event studies, we assume that information management incidents create the opportunity for adverse events to occur during care. In this study, we focus on the effects of information management practices and information behaviors on patient safety, and more specifically, on medication administration errors, complaints from patients or their families, and adverse events related to information management as presented in the hypothesized model ( $\triangleright$ Figure 1$)$.

Organizational culture has been linked to many aspects of organizational behavior, including health care performance and safety $[3,19,20]$, and an appropriate organizational culture seems to help reduce adverse events [21]. Further, information culture is positively associated with practices and activities that lead to successful performance in an organization [20]. However, to our knowledge, only a few studies have connected information culture and patient safety $[20,22]$. Some evidence suggests that the elements of information culture may be associated with safety out- comes, but more evidence is needed to confirm this relation [20].

\section{Objective}

The purpose of the study was to test a theoretical model for the stages of development of organizational accidents [13] applied to information management in hospitals to link the elements of information culture in acute care hospitals to information management incidents and patient safety outcomes. We developed and evaluated a structural equation model that describes how organizational factors are associated with work processes and outcomes. Research questions and hypotheses (see $>$ Figure 1) were based on Reason's model for the stages of development of organizational accidents [13] and previous studies of causes and contributing factors for adverse events $[6,7,11,18]$. Each hypothesis includes one or more paths.

1. How are the aspects of information culture connected to each other and to information management incidents?

- H1: An organization's guidance on information management practices is positively related to how electronic patient records (EPRs) are utilized.

- H2: An organization's guidance on information management practices is positively related to information availability in care situations.

- H3: Information availability, an organization's guidance on information management practices, and how EPRs are utilized reduce the loss of information in care situations.

- H4: Information availability, an organization's guidance on information management practices, and how EPRs are utilized reduce documentation errors and information delays in care situations.

2. What conditions in information management create adverse events?

- H5: The loss of important patient care information during shift changes or when patients are transferred from one unit to another increases information delays in care. 
Table 1

Survey items and descriptive statistics of the constructs and variables used in the hypothesized model.

\begin{tabular}{|c|c|c|}
\hline Variable $(n=909)$ & $\alpha$ & Mean \\
\hline Information availability (5 items) & 0.77 & $4.18^{*}$ \\
\hline \multicolumn{3}{|l|}{ Electronic patient data are available when needed. } \\
\hline \multicolumn{3}{|l|}{ I have access to electronic patient data when needed. } \\
\hline \multicolumn{3}{|l|}{ I trust the accuracy of electronic patient data. } \\
\hline \multicolumn{3}{|l|}{ I have access to electronic databases that I need for patient care. } \\
\hline \multicolumn{3}{|l|}{ Once electronically documented, patient data are available to for all health professionals. } \\
\hline Organization's guidance (5 items) & 0.79 & $3.79 *$ \\
\hline \multicolumn{3}{|l|}{ In this unit, we have uniform written guidelines for use of electronic patient data. } \\
\hline \multicolumn{3}{|l|}{ In this unit, we have uniform written guidelines for transfer of patient data between organizations. } \\
\hline \multicolumn{3}{|l|}{ In this unit, we have uniform written guidelines for electronic documentation of patient data. } \\
\hline \multicolumn{3}{|l|}{ I am aware of clinical guidelines used in my organization. } \\
\hline \multicolumn{3}{|l|}{ I am aware of general guidelines used in my organization. } \\
\hline Utilization of EPRs (7 items) & 0.77 & $3.41^{*}$ \\
\hline \multicolumn{3}{|l|}{ I mainly document patient data in electronic records. } \\
\hline \multicolumn{3}{|l|}{ I receive the most current patient data from electronic information systems. } \\
\hline \multicolumn{3}{|l|}{ Once electronically documented, patient data are not manually copied to patient records. } \\
\hline \multicolumn{3}{|l|}{ Once electronically documented, patient data are not copied to other information systems. } \\
\hline \multicolumn{3}{|l|}{ In this unit, handwritten patient records are not used alongside electronic patient records. } \\
\hline \multicolumn{3}{|l|}{ Once electronically documented, patient data are available to all health professionals. } \\
\hline \multicolumn{3}{|l|}{ I utilize reports from electronic databases in my job. } \\
\hline Information delay (2 items) & 0.81 & $2.53^{*}$ \\
\hline \multicolumn{3}{|l|}{ Patient data were not available when I needed them. } \\
\hline \multicolumn{3}{|l|}{ I received changes in patient's care regimen with delay. } \\
\hline Documentation error (4 items) & 0.76 & $1.92^{*}$ \\
\hline \multicolumn{3}{|l|}{ I did not document patient data immediately. } \\
\hline \multicolumn{3}{|l|}{ I forgot to document necessary patient data. } \\
\hline \multicolumn{3}{|l|}{ I did not remember all details when documenting patient data. } \\
\hline \multicolumn{3}{|l|}{ I documented inaccurate data. } \\
\hline Information-related adverse event ( 2 items) & 0.91 & $0.52^{*}$ \\
\hline \multicolumn{3}{|l|}{ Inaccurate data have caused adverse event or a near-miss situation. } \\
\hline \multicolumn{3}{|l|}{ Missing data have caused adverse event or a near-miss situation. } \\
\hline Important patient care information is often lost during shift changes. * * & . & 2.46 \\
\hline Things "fall between the cracks" when transferring patients from one unit to another.* * & . & 2.99 \\
\hline Medication administration errors** & . & 2.04 \\
\hline Complaints from patients or their families** & . & 1.28 \\
\hline
\end{tabular}

. Logically impossible to present.

* Item means.

** Items from RN4CAST nurse questionnaire.
- H6: Documentation errors increase information losses during shift changes and when patients are transferred from one unit to another.
- H7: The loss of important patient care information during shift changes or when patients are transferred from one unit to another increases medication errors, complaints from patients or their families, and information-related adverse events.

- H8: Information management incidents increase medication errors, complaints 
from patients or their families, and information-related adverse events.

- H9: Medication errors increase the occurrence of complaints from patients or their families.

- H10: Information-related adverse events increase the occurrence of complaints from patients or their families.

\section{Methods}

\subsection{Data Collection}

Using a cross-sectional design, data were gathered with a survey of nurses conducted in conjunction with data collection for the multi-country, cross-sectional Nurse Forecasting: Human Resources Planning in Nursing (RN4CAST) study funded by the 7th Framework Program of the European Commission [23]. The current study partly utilizes the data from the Finnish sample.

Registered nurses (RNs) in surgical and medical units at acute care hospitals in Finland were surveyed between October 2009 and February 2010. In total, 32 acute care hospitals with at least 100 beds were selected using purposive stratified sampling based on geographic location. We invited 2463 RNs at 130 units to complete the questionnaire, distributed as an electronic survey template. RNs were defined as those meeting the European Union definition of trained and licensed nurses according to directive 2005/36/EC. The invitation to participate, with a link to the web-based questionnaire, was sent to nurses via e-mail either by the researchers or by the head nurse of the unit. The latter option was used when hospital policy prohibited the distribution of staff e-mail addresses to researchers.

\subsection{Variables and Measures}

We utilized items of Finnish data from the nurse survey questionnaire designed for the RN4CAST study [23]. A section with 34 items related to information management factors that could contribute to adverse events was added to the questionnaire used in Finland. The structure of these questions was based on Reason's (2001) stages of development of organizational accidents, in which organizational and corporate culture - including management decisions, processes, and information systems - can have negative consequences. These concepts were operationalized under three headings: information management practices (9 items), information behaviors (14 items), and information management incidents (11 items). The items were derived from the results of previous research in information management $[6,7]$ and information culture studies $[1,2]$ on the

Table 2 Demographics of the respondents and descriptive statistics of the study variables.

\begin{tabular}{|l|l|l|l|l|l|l}
\hline Variable ( $\mathbf{n}=\mathbf{9 0 9})$ & $\mathbf{n}$ & $\%$ & Mean & SD & Min & Max \\
\hline Age (in years) & 875 & & 41.38 & 10.36 & 22 & 63 \\
\hline Work experience in this hospital (in years) & 896 & & 10.64 & 8.93 & 0 & 38 \\
\hline Work experience as a nurse (in years) & 901 & & 13.82 & 9.44 & 0 & 40 \\
\hline Hospital type & 909 & & & & & \\
\hline University hospital & 154 & 17 & & & & \\
\hline Central hospital & 637 & 70 & & & & \\
\hline Other & 118 & 13 & & & & \\
\hline Unit & 904 & & & & & \\
\hline Surgical & 402 & 45 & & & & \\
\hline Medical & 467 & 51 & & & & \\
\hline Surgical/Medical & 35 & 4 & & & & \\
\hline Gender & 903 & & & & & \\
\hline Female & 875 & 97 & & & & \\
\hline Male & 28 & 3 & & & & \\
\hline
\end{tabular}

causes of and the factors that contribute to information breakdowns. The survey items are presented in $>$ Table 1 along with the means and the Cronbach alphas for the study variables. All constructs had alpha values ranging from 0.773 to 0.912 , indicating good construct reliability.

We measured information management practices and information behaviors using three latent constructs in the analysis: information availability, organizational guidance, and utilization of EPRs ( Table 1). Information availability included five statements concerning the accuracy and availability of electronic patient data, and access to electronic databases when needed. Organization's guidance (three statements) concerned the existence of guidance for the use, transfer, and documentation of electronic patient data and respondents' awareness of guidelines. The seven items representing the utilization of EPRs concerned documentation practices, the use of handwritten patient records alongside EPRs and the utilization of electronic databases. Respondents were invited to reflect on the extent to which the statements aligned with the organization, using a fivepoint scale (strongly agree, agree, neither, disagree, and strongly disagree).

Information management incidents were measured using two latent constructs: documentation errors and information delay ( Table 1). The documentation errors construct represents the respondent's perception of the occurrence of errors in documenting patient information. The information delay construct is based on two statements concerning delays in the transfer of patient information during care. For these variables, respondents were asked, "How often would you say each of the following incidents occurs involving you or your patients?" Response options ranged from never (0) to daily (6). In addition, two measurable variables were added to the model: 1) Important patient care information is often lost during shift changes, and 2) things "fall between the cracks" when transferring patients from one unit to another. Respondents were invited to reflect on the extent to which the statements aligned with the organization, using a fivepoint scale (strongly agree, agree, neither, disagree, and strongly disagree). 


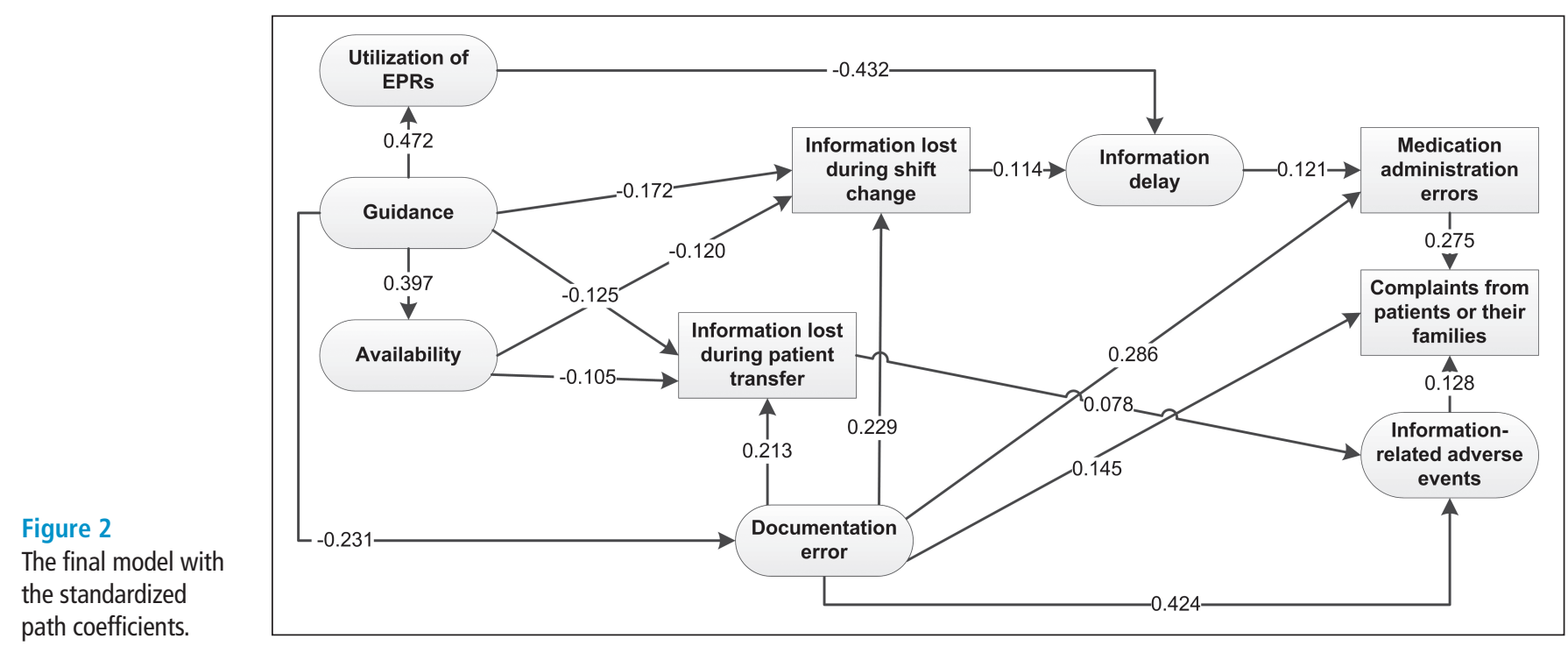

As described in the theoretical model $(\triangleright$ Figure 1$)$, the following patient safety outcomes served as outcome variables and were measured with the nurses' reports of frequency of occurrence: complaints from patients or their families, medication administration errors, and adverse events in which a contributing factor included missing or inaccurate data. The first two variables were assessed using single items, whereas the latter variable included two additional items: 1) Missing data caused adverse events or a near-miss situation in patient care, and 2) inaccurate data caused adverse events or a near-miss situation in patient care. Using a seven-point Likert scale, nurses were asked to assess the incidence of patient safety outcomes ranging from never (0) to daily (6).

\subsection{Ethics}

This study was approved by the Central Ethics Committee of the Northern Savo Hospital District. Each participating hospital granted permission to collect the data. All participants were informed that the collected data would be analyzed in an anonymous form and that participation was voluntary. Completing and returning the survey were taken to indicate informed consent.

\subsection{Statistical Analysis}

We used structural equation modeling (SEM) as the primary analytical technique to assess how well the hypothesized model fit the study data [24]. In the first phase of the analysis, the measurement models of information management practices and information behaviors, information management incidents, and patient safety outcomes were created to verify the measures. The hypothesized model was then evaluated using SEM. We used maximum likelihood estimation as the estimation method and listwise deletion as a method for handling missing values. During the analysis, the hypothesized model was modified as follows: First, the path was deleted if the parameter estimates were not statistically significant $(p>0.05)$. Then, the modification indices were consulted to find statistically and theoretically justified modifications. We used several criteria to evaluate the fit of the final model: $\chi^{2}$ with degrees of freedom, the comparative fit index (CFI), and the root mean square error of approximation (RMSEA) [24, 25]. Analyses were conducted using IBM SPSS Amos version 21.0.0 (Amos Development Corporation; Meadville, PA, USA).

\section{Results}

A total of 909 responses were analyzed, for a response rate of $37 \%$. Table 2 presents the demographics of the survey respondents.

- Figure 2 presents the final model with the empirical results. The model contained 24 items describing six latent constructs (the ellipsis points): utilization of EPRs, guidance, availability, documentation error, information delay, and informationrelated adverse event. In addition, four measured variables (the rectangle) were included in the model. The results gave a $\chi^{2}$ value of $813.548, \mathrm{df}=326$, with a $\mathrm{p}<0.001$, which indicates the poor fit of the model. However, the $\chi^{2}$ test is very sensitive to sample size, meaning that a large sample in the model will result in a statistically significant result even when the fit of the data to the model is good [25]. Nevertheless, the ratio of $\chi^{2}$ to $d f$ was 2.496 , which is less than three and thus indicated a good fit. The incremental fit indices and the RMSEA also indicated a good fit of the data to the hypothesized model $(\mathrm{CFI}=0.95$; RMSEA $=0.04$, with a $90 \%$ confidence interval of 0.037 $0.044)$. For categorical data, $\mathrm{CFI} \geq 0.95$ and RMSEA $<0.06$ indicated a good fit $[24,25]$. For a model of this complexity and sample size, a CFI value greater than 0.90 indicated a very good fit. Therefore, we conclude that these measures reflect a good model fit.

The model presented in $>$ Figure 2 explained $16 \%, 22 \%, 23 \%$, and $5 \%$ of the variance in the availability, utilization of EPRs, information delay, and documentation errors, respectively, and $20 \%$ of the variance of adverse events related to infor- 
Table 3 Standardized direct and indirect total effects of the organizational factors (columns) on information management incidents and patient safety outcomes (rows).

\begin{tabular}{|c|c|c|c|c|c|c|c|c|c|c|}
\hline & & Guidance & 1 & 2 & 3 & 4 & 5 & 6 & 7 & 8 \\
\hline \multicolumn{11}{|c|}{ Standardized Total Effects } \\
\hline 1 & Documentation error & -0.231 & - & - & - & - & - & - & - & - \\
\hline 2 & Availability & 0.397 & - & - & - & - & - & - & - & - \\
\hline 3 & Utilization of EPRs & 0.472 & - & - & - & - & - & - & - & - \\
\hline 4 & Information lost during shift change & -0.272 & 0.229 & -0.120 & - & - & - & - & - & - \\
\hline 5 & Information delay & -0.235 & 0.026 & -0.014 & -0.432 & 0.114 & - & - & - & - \\
\hline 6 & Information lost during patient transfer & -0.215 & 0.213 & -0.105 & - & - & - & - & - & - \\
\hline 7 & Information-related adverse events & -0.115 & 0.441 & -0.008 & - & - & - & 0.078 & - & - \\
\hline 8 & Medication administration errors & -0.094 & 0.289 & -0.002 & -0.052 & 0.014 & 0.121 & - & - & - \\
\hline 9 & Complaints from patients or their families & -0.074 & 0.281 & -0.002 & -0.014 & 0.004 & 0.033 & 0.010 & 0.128 & 0.275 \\
\hline \multicolumn{11}{|c|}{ Standardized Direct Effects } \\
\hline 1 & Documentation error & -0.231 & - & - & - & - & - & - & - & - \\
\hline 2 & Availability & 0.397 & - & - & - & - & - & - & - & - \\
\hline 3 & Utilization of EPRs & 0.472 & - & - & - & - & - & - & - & - \\
\hline 4 & Information lost during shift change & -0.172 & 0.229 & -0.120 & - & - & - & - & - & - \\
\hline 5 & Information delay & - & - & - & -0.432 & 0.114 & - & - & - & - \\
\hline 6 & Information lost during patient transfer & -0.125 & 0.213 & -0.105 & - & - & - & - & - & - \\
\hline 7 & Information-related adverse events & - & 0.424 & - & - & - & - & 0.078 & - & - \\
\hline 8 & Medication administration errors & - & 0.286 & - & - & - & 0.121 & - & - & - \\
\hline 9 & Complaints from patients or their families & - & 0.145 & - & - & - & - & - & 0.128 & 0.275 \\
\hline \multicolumn{11}{|c|}{ Standardized Indirect Effects } \\
\hline 1 & Documentation error & - & - & - & - & - & - & - & - & - \\
\hline 2 & Availability & - & - & - & - & - & - & - & - & - \\
\hline 3 & Utilization of EPRs & - & - & - & - & - & - & - & - & - \\
\hline 4 & Information lost during shift change & -0.101 & - & - & - & - & - & - & - & - \\
\hline 5 & Information delay & -0.235 & 0.026 & -0.014 & - & - & - & - & - & - \\
\hline 6 & Information lost during patient transfer & -0.091 & - & - & - & - & - & - & - & - \\
\hline 7 & Information-related adverse events & -0.115 & 0.017 & -0.008 & - & - & - & - & - & - \\
\hline 8 & Medication administration errors & -0.094 & 0.003 & -0.002 & -0.052 & 0.014 & - & - & - & - \\
\hline 9 & Complaints from patients or their families & -0.074 & 0.136 & -0.002 & -0.014 & 0.004 & 0.033 & 0.010 & - & - \\
\hline
\end{tabular}

mation management. In total, 18 of the 32 paths tested were statistically significant and accepted in the final model ( $>$ Figure 2 ). The standardized direct and indirect total effects are presented in $>$ Table 3 .

As a result, hypotheses $\mathrm{H} 1, \mathrm{H} 2, \mathrm{H} 6, \mathrm{H} 9$, and $\mathrm{H} 10$ are accepted as the coefficients between the variables are statistically significant ( Figure 2), but H3 (information availability, an organization's guidance on information management practices, and how EPRs are utilized to reduce the loss of information in care situations), H4 (information availability, an organization's guidance on information management practices, and how EPRs are utilized to reduce documentation errors and information delays in care), H5 (the loss of important patient care information during shift changes or when the transfer of patients from one unit to another increases information delays in care), H7 (the loss of im- portant patient care information during shift changes or when the transfer of patients from one unit to another increases medication errors, complaints from patients or their families, and information-related adverse events), and H8 (information management incidents increase medication errors, complaints from patients or their families, and information-related adverse events) are only partially accepted. 


\section{Discussion}

In this study, we tested a theoretical model of the stages of development of organizational accidents [13] that links information culture to information management incidents and, subsequently, patient safety outcomes. The results of the structural model confirm that patient safety outcomes are associated with the elements of the information culture that create conditions that generate errors in hospitals. However, although these relations are correlations that are consistent with the hypothesized causations, the relations should not be considered actual proof of causation.

We found that guidance from organizations, such as written guidelines for the use and documentation of electronic patient data, was associated with the utilization of EPRs and information availability constructs ( $\mathrm{H} 1$ and $\mathrm{H} 2)$. Guidance has a direct or indirect effect on all other latent constructs and variables in this study. It seems that better guidance and nurses' awareness of it correlates with fewer information management incidents and a decrease in the number of medication administration errors, complaints from patients or their families, and information-related adverse events. The findings of a systematic review conducted by Lawton et al. (2012) support this result. According to their study, incomplete guidance regarding appropriate performance of work tasks and processes is a latent contributing factor for adverse events [26]. Organizational guidance should be based on national-level regulations, such as laws, regulations, and policies, but organizations' information culture and local conditions also affect information management practices and information behaviors [1]. Together with information technology (e.g., EPRs in hospitals), information management practices and behaviors define an organization's ability to process information safely $[3,27]$.

Better organizational guidance regarding information management practices and information availability reduced the loss of information during shift changes or patient transfers, but utilization of EPRs was not connected with either of the information loss variables (H3). In addition, organi- zational guidance reduced documentation errors, and utilization of EPRs reduced information delays in care, but information availability did not statistically significantly affect these factors (H4). Further, although utilization of EPRs concerned items related to the use of handwritten patient records and the copy-paste method to transfer patient data, which are typical documentation-related causes for adverse events [28, 29, 30, 31], the utilization of EPRs was not correlated with documentation errors or organizational guidance on information delays in care. Thus, the final model did not support the results of previous studies $[28,29,30,31]$; however, the results might have been different if we had analyzed only the direct relation between utilization of EPRs and patient safety outcomes.

The variables and constructs that represent information management incidents in this study partially correlated with each other. The loss of important patient care information during shift changes increased information delays in care, but if information loss occurred when patients were transferred from one unit to another, then the path was not statistically significant (H5). However, the requirements of handovers before intra-hospital transfers differ from those of inter-shift handovers because the specific information needs in different clinical settings are not similar [17]. Documentation errors increased information losses during shift changes and when patients were transferred from one unit to another (H6). According to previous studies, accurate documentation of patient data is a central element of continuity of care [32, $33,34]$, but inaccurate and insufficient content in documentation might lead to incomplete information transfer [32].

Hypothesis 7 suggested that loss of information has an effect on patient safety outcomes. Only the loss of important patient care information when patients were transferred from one unit to another directly increased information-related adverse events; however, this loss of information was not directly connected to other outcome variables. Previous studies have shown that failures in intra-hospital information transfer $[16,17]$ and failures in information transfer between organizations $[35,36]$ are common, and poor handovers are associated with adverse events [17, 37]. In the present study, the loss of important patient care information during shift changes had an indirect effect on medication errors and complaints from patients or their families but was not associated with information-related adverse events. During clinical care, appropriate communication is a vital element of safe patient care, as failures during information management processes are one of the main causes of adverse events [38].

Documentation errors were associated with medication administration errors, complaints from patients or their families, and information-related adverse events, whereas only information delays were directly associated with medication administration errors and had an indirect effect on complaints (H8). Our findings confirmed a statistically significant relation between documentation errors and medication administration errors suggested by a previous systematic review [11]. This means that not all documentation errors are observed when medications are prepared for patients. In this study, documentation errors had the strongest total effect on all measured patient safety outcomes but were also connected to information loss during shift change or patient transfer, which indicates the important role of written communication when improving patient safety, as suggested by previous studies $[16,32,35$, 39]. Based on the results, documentation errors were affected by organizational guidance. Consequently, as one tactic, hospitals should focus on standardizing documentation practices, for example, using structured documentation, which has been shown to improve continuity of care and patient safety [33].

The final model of this study was complex, with multiple connections between latent and measured variables, and information management incidents seem to have a mediating effect rather than a direct effect. These factors might explain why all fit indices did not support the model. However, simplifying the model would have left out some items that are important in terms of the development of organizational accidents in the information management context. Our model explained only a minor portion (5-23\%) of the variance, indicating 
that other factors, such as elements of the work environment $[40,41,42]$, the patient safety culture [43], and patient safety management $[43,44]$, affect patient safety outcomes. In addition, organizational culture has been linked to many aspects of organizational behavior, including health care performance and safety $[3,19,20]$, and an appropriate organizational culture might help to reduce adverse events [21].

We acknowledge this study has a number of limitations that should be taken into account when the results are interpreted. First, in addition to the variables included in the study, other variables related to the use of EPRs in hospitals might contribute to the development of adverse events. For example, certain documentation tasks might be complex in an electronic environment, and health professionals' competence in using EPRs is not uniform. In this study, these issues are not accounted for the model. However, the effects of these variables in the development of adverse events should be studied in the future. Second, the sample included only medical and surgical units in hospitals that offer acute care. Consequently, other units may have a different culture because of the nature of their work. For that reason, these results are not necessarily generalizable to all health care settings. Third, the data were collected using a self-administered survey, and a listwise method was used to handle missing values; the response rate was $37 \%$. Every effort was made to increase this rate. Two reminders were sent to respondents, and hospitals with $\mathrm{RN}$ response rates of less than $40 \%$ were asked to try and motivate RNs to respond. Nevertheless, the age and gender distribution of the sample correspond to studies of other similar populations in Finland. Fourth, the cross-sectional design of this study precluded strong statements on causality. For that reason, the results are not actual proof of causation between study variables, but the results indicate correlations.

Last, all outcomes were assessed through nurse reports, which are subjective evaluations and may be biased. However, these evaluations indicate nurses' perceptions of the frequency of adverse events in their hospital. As RNs are on the front line in patient care, their evaluations are con- sidered trustworthy and are used when more reliable data are not available [43]. Currently, hospital discharge data sets do not include measured information about adverse events, and other comprehensive adverse event data and statistics do not exist. This study focused on adverse events as patient safety outcomes; thus, we decided to rely on nurses' reflections in this matter. The patient safety outcomes used in this study are nursing sensitive and are used as quality indicators in nursing [45]. However, to validate and strengthen the results, connections should be tested using objective organizational and outcome data when possible.

This study was conducted to test directional relations between three latent constructs (utilization of EPRs, organizational guidance, and information availability), information management incidents, and patient safety outcomes. The final model showed that of the three information management and behavior factors, guidance had the strongest effect on information management incidents, while the utilization of EPRs was associated with fewer information delays in care. Further, stronger guidance was associated with a decreased rate of documentation errors, whereas documentation errors were correlated with increases in medication administration errors, complaints from patients and their families, and information-related adverse events. These results connect organizational guidance regarding information management and patient safety outcomes. Documentation errors seem to have a mediating effect. To prevent adverse events, preventive actions on these latent variables should also be targeted.

\section{Conclusions}

The dimensions of the information culture create working conditions that might decrease patient safety in hospitals. The structural factor organizational guidance seemed to have the strongest effect on information management incidents and, further, on patient safety outcomes in terms of information management in acute care hospitals. In addition, uniform organizational guidance improved the utilization of EPRs and the availability of data. Further, better utilization of EPRs indicated reduced information delays in care. The presence of documentation errors was associated with an increase in all patient safety outcomes. The study results emphasize the importance of uniform written guidelines for information management practices and the meaning of the documentation of patient data when improving patient safety.

\section{Acknowledgment}

We would like to thank Professor Juha Kinnunen (University of Eastern Finland) and Dr. Anneli Ensio (University of Eastern Finland), who led the Finnish branch of the RN4CAST study.

\section{References}

1. Choo CW, Furness C, Paquette S, van den Berg H, Detlor B, Bergeron P, et al. Working with information: information management and culture in a professional services organization. J Inf Sci. 2006; 32(6): 491-510

2. Choo CW, Bergeron P, Detlor B, Heaton L. Information culture and information use: An exploratory study of three organizations. J Am Soc Inf Sci Technol. 2008; 59(5): 792-804.

3. Choo CW. Information culture and organizational effectiveness. Int J Inf Manage. 2013; 33(5): 775-779.

4. Marchand DA, Kettinger WJM, Rollins JD. Information orientation: People, technology and the bottom line. Sloan Manage Rev. 2000; 41(4): 69-80.

5. Choo CW. Information Management for the Intelligent organization. The Art of Scanning the Environment. 3rd ed. Medford, New Jersey: Information Today, Inc.; 2002.

6. Jylhä V, Saranto K, Bates DW. Preventable adverse drug events and their causes and contributing factors: the analysis of register data. Int J Qual Health Care. 2011; 23(2): 187-197.

7. Jylhä V, Bates DW, Saranto K. Adverse events and near misses relating to information management in a hospital. HIM J. 2016; 45(2): 55-63.

8. Berdot S, Gillaizeau F, Caruba T, Prognon P, Durieux $\mathrm{P}$, Sabatier B. Drug administration errors in hospital inpatients: a systematic review. PLoS One. 2013; 8(6): e68856.

9. Keers RN, Williams SD, Cooke J, Ashcroft DM. Prevalence and nature of medication administration errors in health care settings: a systematic review of direct observational evidence. Ann Pharmacother. 2013; 47(2): 237-256.

10. Elliott M, Page K, Worrall-Carter L. Reason's accident causation model: application to adverse events in acute care. Contemp Nurse. 2012; 43(1): 22-28. 
11. Keers RN, Williams SD, Cooke J, Ashcroft DM. Causes of medication administration errors in hospitals: a systematic review of quantitative and qualitative evidence. Drug Saf. 2013; 36(11): 1045-1067.

12. van Beuzekom M, Boer F, Akerboom S, Hudson P. Patient safety: latent risk factors. Br J Anaesth. 2010; 105(1): 52-59.

13. Reason JT. Understanding adverse events: the human factor. In: Vincent C, editor. Clinical Risk Management: Enhancing Patient Safety. 2nd ed. London: BMJ Books; 2001. p. 9-30.

14. Elliott M, Worrall-Carter L, Page K. Factors contributing to adverse events after ICU discharge: a survey of liaison nurses. Aust Crit Care. 2013; 26(2): 76-80.

15. Lederman RM, Parkes C. Systems failure in hospitals--using Reason's model to predict problems in a prescribing information system. J Med Syst. 2005; 29(1): 33-43.

16. Nagpal K, Vats A, Lamb B, Ashrafian H, Sevdalis $\mathrm{N}$, Vincent $\mathrm{C}$, et al. Information Transfer and Communication in Surgery: A Systematic Review. Ann Surg. 2010; 252(2): 224-239.

17. Ong MS, Coiera E. A systematic review of failures in handoff communication during intrahospital transfers. Jt Comm J Qual Patient Saf. 2011; 37(6): 274-284.

18. Vermeir P, Vandijck D, Degroote S, Peleman R, Verhaeghe R, Mortier E, et al. Communication in healthcare: a narrative review of the literature and practical recommendations. Int J Clin Pract. 2015; 69(11): 1257-1267.

19. Scott T, Mannion R, Marshall M, Davies H. Does organisational culture influence health care performance? A review of the evidence. J Health Serv Res Policy. 2003; 8(2): 105-117.

20. Westrum R. A typology of organisational cultures. Qual Saf Health Care. 2004; 13(suppl 2): ii22-ii27.

21. Hartmann CW, Meterko M, Rosen AK, Shibei Zhao, Shokeen P, Singer S, et al. Relationship of Hospital Organizational Culture to Patient Safety Climate in the Veterans Health Administration. Med Care Res Rev. 2009; 66(3): 320-338.

22. MacIntosh-Murray A, Choo CW. Information behavior in the context of improving patient safety. J Am Soc Inf Sci Technol. 2005; 56(12): 1332-1345.

23. Sermeus W, Aiken L, Van dH, Rafferty AM, Griffiths P, Moreno-Casbas M, et al. Nurse Forecasting in Europe (RN4CAST): Rationale, design and methodology. BMC Nurs. 2011; 10(1): 6 .
24. Hair J, Black W, Babin B, Anderson R. Multivariate data analysis. A global perspective. 7th ed. Upper Saddle River (NJ): Pearson Education; 2010.

25. Schreiber JB. Core reporting practices in structural equation modeling. Research in Social and Administrative Pharmacy. 2008; 4(2): 83-97.

26. Lawton R, McEachan RRC, Giles SJ, Sirriyeh R, Watt IS, Wright J. Development of an evidencebased framework of factors contributing to patient safety incidents in hospital settings: a systematic review. BMJ Qual Saf. Epub 2012 March 15. doi: 10.1136/bmjqs-2011-000443.

27. Marchand DA, Kettinger WJ, Rollings JD. Information Orientation. The Link to Business Performance. New York: Oxford University Press; 2002.

28. Safran C, Reti S, Marin HF, editors. Do Electronic Information Systems Facilitate Errors in Medication Management? In: Medinfo 2010 - Proceedings of the 13th World Congress on Medical Informatics; 2010.

29. Bowman S. Impact of electronic health record systems on information integrity: quality and safety implications. Perspect Health Inf Manag. 2013; 10: $1 c$.

30. American Health Information Management Association [Internet]. Appropriate use of the copy and paste functionality in electronic health records; 2014 [cited 2016 Nov 28]. Available from: http://bok.ahima.org/PdfView?oid=300306.

31. ECRI Institute, Health Technology Assessment Information Service [Internet]. Copy/Paste: Prevalence, Problems, and Best Practices; 2015 [cited 2016 Nov 28]. Available from: http://www.ecri.org/ Resources/HIT/CP_Toolkit/CopyPaste_Literature_final.pdf.

32. Braaf S, Manias E, Riley R. The role of documents and documentation in communication failure across the perioperative pathway. A literature review. Int J Nurs Stud. 2011; 48(8): 1024-1038.

33. Saranto K, Kinnunen UM, Kivekas E, Lappalainen AM, Liljamo P, Rajalahti E, et al. Impacts of structuring nursing records: a systematic review. Scand J Caring Sci. 2014; 28(4): 629-647.

34. Sondergaard SF, Lorentzen V, Sorensen EE, Frederiksen $\mathrm{K}$. The documentation practice of perioperative nurses. A literature review. J Clin Nurs. Epub 2016 Jun 21. doi: 10.1111/jocn.13445.

35. Kripalani S, LeFevre F, Phillips CO, Williams MV, Basaviah P, Baker DW. Deficits in Communication and Information Transfer Between Hospital-Based and Primary Care Physicians. J Am Med Inform Assoc. 2007; 297(8): 831-841.

36. Kattel S, Manning DM, Erwin PJ, Wood H, Kashiwagi DT, Murad MH. Information Transfer at Hospital Discharge: A Systematic Review. J Patient Saf. Epub 2016 Jan 7. doi: 10.1097/ PTS.0000000000000248.

37. Segall N, Bonifacio AS, Schroeder RA, Barbeito A, Rogers D, Thornlow DK, et al. Can we make postoperative patient handovers safer? A systematic review of the literature. Anesth Analg. 2012; 115(1): 102-115.

38. Smeulers M, Lucas C, Vermeulen H. Effectiveness of different nursing handover styles for ensuring continuity of information in hospitalised patients. Cochrane Database Syst Rev. 2014; 6: CD009979.

39. Braaf S, Riley R, Manias E. Failures in communication through documents and documentation across the perioperative pathway. J Clin Nurs. 2015; 24(13-14): 1874-1884.

40. Spence Laschinger HK, Leiter MP. The impact of nursing work environments on patient safety outcomes: the mediating role of burnout/engagement. J Nurs Adm. 2006; 36(5): 259-267.

41. Tervo-Heikkinen T, Partanen P, Aalto P, Vehviläinen-Julkunen K. Nurses' work environment and nursing outcomes: A survey study among Finnish university hospital registered nurses. Int J Nurs Pract. 2008; 14(5): 357-365.

42. Kirwan M, Matthews A, Scott PA. The impact of the work environment of nurses on patient safety outcomes: A multi-level modelling approach. Int J Nurs Stud. 2013; 50(2): 253-263.

43. Ausserhofer D, Schubert M, Desmedt M, Blegen MA, De Geest S, Schwendimann R. The association of patient safety climate and nurse-related organizational factors with selected patient outcomes: A cross-sectional survey. Int J Nurs Stud. 2013; 50(2): 240-252.

44. Tvedt C, Sjetne IS, Helgeland J, Bukholm G. A cross-sectional study to identify organisational processes associated with nurse-reported quality and patient safety. BMJ Open. 2012; 2(6): e001967.

45. Maben J, Morrow E, Ball J, Robert G, Griffiths P [Internet]. High quality care metrics for nursing. National Nursing Research Unit, King's College London; 2012 [cited 2016 Nov 28]. Available from: http://eprints.soton.ac.uk/346019/1/High-QualityCare-Metrics-for-Nursing----Nov-2012.pdf. 